\title{
Bilateral double testicular arteries: a case report and review of the literature. Potential embryological and surgical considerations
}

\author{
G.K. Paraskevas, K. Natsis, Z. Nitsa, B. Papaziogas, P. Kitsoulis \\ Department of Anatomy, Faculty of Medicine, Aristotle University of Thessaloniki, Greece
}

[Received 13 November 2013; Accepted 2 January 2014]

\begin{abstract}
The aberrancies concerning the number, origin and course of the testicular arteries are found in an incidence of approximately $4.7-20 \%$ in the literature and are documented less frequently than the respective variations of the homonymous veins. In the current study, a very rare complex of testicular arteries' variations is described, in which the occurrence of bilateral double testicular arteries is recorded. Particularly, apart from the normal testicular arteries on each side, we observed an additional right testicular artery originated from the ipsilateral renal artery and an additional left testicular artery taking its origin from the abdominal aorta just above the renal artery's origin site; the latter additional testicular artery arched above the left renal vein. Both, the bilateral double testicular arteries accompanied the testicular vein on each side as their satellite arteries. We discuss the potential embryological development of that complex of arterial variants, their likely clinical and surgical applications, as well as we proceed on a brief review of the relevant literature. (Folia Morphol 2014; 73, 3: 383-388)
\end{abstract}

Key words: duplication, embryological origin, significance, testicular artery, variation

\section{INTRODUCTION}

The variants of testicular artery (TA) regarding its number, origin and course are detected less frequently than the variations of the testicular veins (TV) [5]. These TA's variations have been estimated in an incidence of $4.7-20 \%[5,22,24,40]$. These aberrancies display significance from a clinical viewpoint since the TA's blood flow was found to be significantly decreased in men with varicocele [46]. Although many cases of double TAs have been documented in the literature $[7,11,32,47]$, the bilateral presence of double TAs is more rarely detected $[22,37]$. In our study, we report on a very rare complex of TAs variants, such as bilateral double TAs with co-existence of TA's high origin from the aorta on the left side and TA's aber- rant origin from the renal artery on the right side. We discuss its likely embryological development, its surgical significance and the relative literature as well.

\section{CASE REPORT}

During the routine dissection of the abdominal region and especially of the retroperitoneal space, we came across a very rare case of bilateral double TAs in an 82-year-old male cadaver. The cadaver, which had been provided to the educational and research anatomical course at our Department of Anatomy, was formalin-fixed and his death was unrelated to causes derived from the urogenital system. In particular, after resection of the anterior abdominal wall, we removed carefully the abdominal organs as well

Address for correspondence: Dr G.K. Paraskevas, Assistant Professor of Anatomy, Aristotle University Campus, Thessaloniki, Greece, PO Box: 300, Postal Code: 54124, tel: 00302310999330, e-mail: g_paraskevas@yahoo.gr 
the retroperitoneum. So far, having obtained a clear vision of the retroperitoneal space we observed the bilateral presence of double TAs. On the right side apart from the main TA arising from its normal origin site from the antero-lateral aspect of the abdominal aorta, we noticed an accessory TA arising from the right renal artery $0.7 \mathrm{~cm}$ after its origin from the aorta. That upper right TA was directed obliquely downwards accompanied after a short distance by the lower right TA and the right TV, as its satellite arteries. On the left side, the main TA was originated from its typical origin site from the abdominal aorta; whereas an accessory upper left TA was noticed arising from the abdominal aorta just proximal to the origin site of the left renal artery. The latter artery was curved arcuately around the upper margin of the left renal vein, crossing its anterior surface after the draining site of the left TV. Afterwards, the upper right TA was directed obliquely downwards accompanying along with the lower left TA the ipsilateral TV, distal to the level of the iliac crest (Fig. 1). There was no finding from the cadaver's medical history to suggest any previous pathologic conditions concerning the urogenital and abdominal vascular system. In addition, no evidence of surgical procedures undertaken in the region and no other associated vascular abnormalities were detected. During the anatomical dissection which was undertaken by means of the classical method of dissection, we carefully exposed and cleaned the great vessels of the retroperitoneal space along with their tributaries. The morphology as well as the topography of the recorded variants were documented by photographs and line drawings. The measurements were made with the assistance of a Vernier electronic digital caliper (Mitutoyo Co, Japan) with an accuracy of $0.1 \mathrm{~mm}$.

\section{DISCUSSION}

The TAs are long and slender arteries arising from the anterolateral aspect of the abdominal aorta, below the renal arteries but above the origin of the inferior mesenteric artery. They are directed under the parietal peritoneum over the psoas muscle. The right TA first crossing the inferior vena cava lies posterior to the horizontal part of the duodenum, right colic and ileocolic arteries, root of the mesentery and terminal ileum, whereas the left TA is lying posterior to the inferior mesenteric vein, left colic artery and descending colon. TA is crossing the ureter, supplying its middle portion and running along the pelvic brim above the
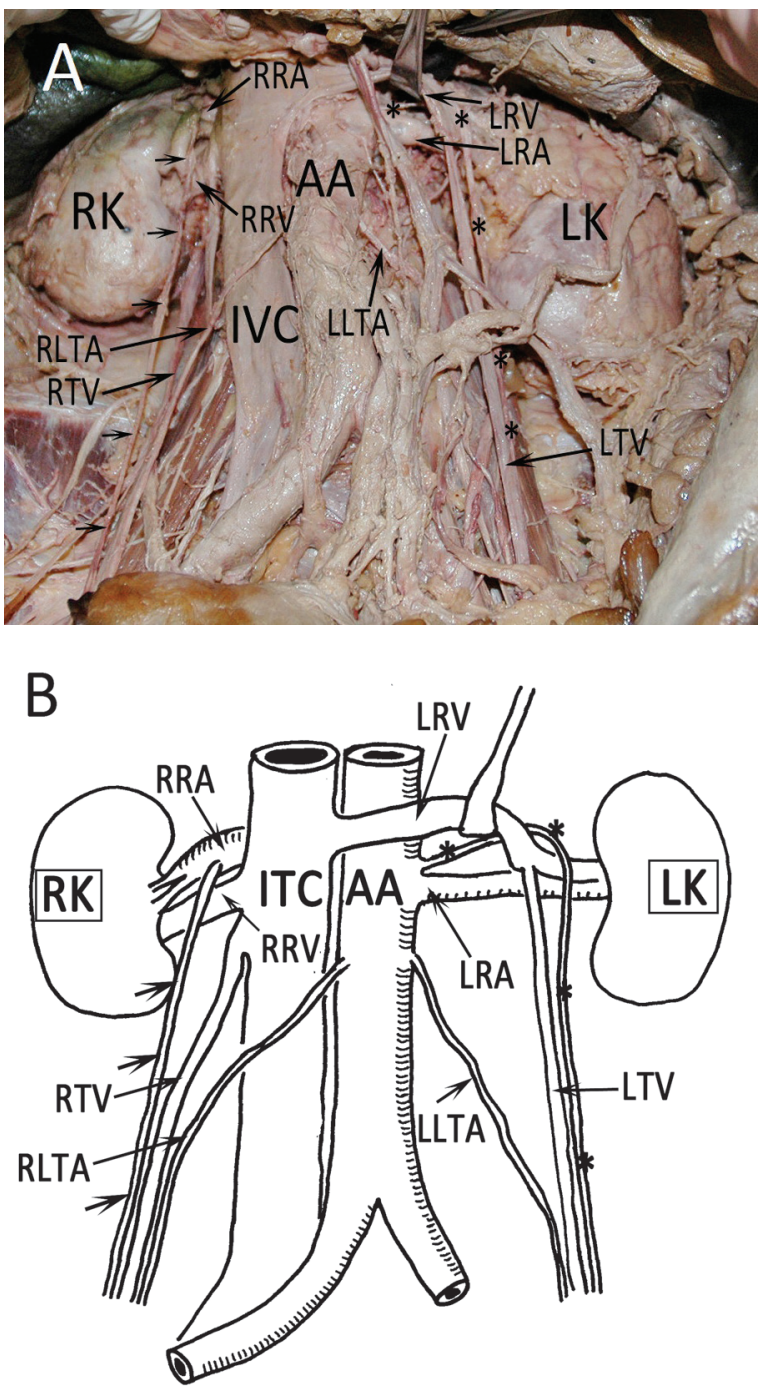

Figure 1. A. Overview of the retroperitoneal space where the right upper testicular artery (small arrows) is demonstrated arising from the right renal artery (RRA) and the left upper testicular artery (asterisks) originating from the abdominal aorta (AA) just proximal to the origin site of the left renal artery (LRA). The left upper testicular artery is shown arching around the left renal vein (LRV). The right (RLTA) and the left lower testicular artery (LLTA) along with the upper testicular arteries accompanied the right (RTV) and the left testicular vein (LTV) as satellite arteries; RRV — right renal vein; RK — right kidney; LK — left kidney; IVC — inferior vena cava; $B$. Schematic representation of the Figure $1 \mathrm{~A}$.

external iliac artery, enters the deep inguinal ring and passes in the spermatic cord to the testis $[26,48]$.

The aberrancies of TAs are not uncommon and are described in the literature. Asala et al. [5] observed TA variants in $4.7 \%$ of their specimens and only on the right side, whereas Pai et al. [32] found variation of the TAs regarding their source of origin, level of the origin and number of the arteries, in $14.7 \%$ of 
cases. Felix [13] found TA's variation incidence being $16 / 180(0.09 \%)$ in a material of human fetuses. Moreover Mamatha et al. [24] found TAs variations in $20 \%$, with the rest cases being normal in their origin, course and number. However, TA's variants regarding their number as well as their course are considered less frequent than the variations of the TVs [5]. TA's variations are more frequent in male fetuses and on the right side [11].

TA may arise from the renal artery, or its branches or the accessory renal artery in $15 \%$ of cases [7]. Lippert and Pabst [22] found such an abnormal origin in $17 \%$ of cases. In particular, they noticed the right TA originated from the ipsilateral renal artery $(6 \%)$, the left TA from the left renal artery (4\%), 2 right TAs from the right renal artery (1\%), 2 TAs on both sides from the renal arteries (1\%), 1 TA stems from both the aorta and a renal artery ( $<1 \%), 2$ TAs on one side 1 from renal artery and 1 from aorta $(<1 \%)$ and 2 left TAs from the left renal artery (< 1\%). Adachi [2] detected an incidence of $16.33 \%$ for the TAs originated from the renal artery, with the same incidence being $10 \%$ [10], 16.1\% [35], 3\% [3], 14.6\% [29], 5.5\% [11], $14 \%$ [40] and 10\% [47].

There are studies referring to TA's origin from an accessory renal artery $[12,38,41,42]$. It is noteworthy that Mamatha et al. [24] noticed that in $20 \%$ of their specimens the variable TAs were associated with accessory renal arteries. In specific, most of these aberrant TAs were originated solely from accessory renal arteries and not main renal arteries. Shoja et al. [40] observed that aberrant TAs tend to originate from kidneys that possess an accessory renal artery. The aberrant TAs mostly are branching from the accessory renal arteries. In our case the right superior TA was originated from the right renal artery crossing the anterior surface of the ipsilateral renal pelvis. The awareness of such an aberrant TA's origin and course may complicate surgical procedures undertaken at the region of renal pedicle, such as angioplasties and aorta's aneurysm surgical treatment or lead to obstruction of the pelviureteral junction due to anterior or posterior TA's course with respect to the renal pelvis [45]. The abnormal TA's origin from the renal artery may lead to infraction of the testis resulting from transcatheter embolisation of a malignant renal tumour [43].

TA may originate in some instances from other sources than the abdominal aorta and the renal and accessory renal arteries, such as middle suprarenal, lumbar, common iliac, internal iliac, celiac trunk, superior mesenteric, inferior phrenic, inferior epigastric artery [1, 22, 25, 27, 47]. TA could be originated or forming a common trunk, or providing as branch the inferior suprarenal artery [14, 18, 33, 34]. The ratio of common origin for the TA and the suprarenal artery has been estimated approximately 1:26 [2]. Very rarely, TA may arise from the thoracic aorta [24] or from an anomalous middle mesenteric artery [28]. Furthermore, rarely, TA may provide branches, such as the inferior phrenic and the superior suprarenal arteries [30]. Lippert and Pabst [22] stated that TA's origin from other vessels is detected in less than $1 \%$ of population.

The presence of double TA has been noted in some instances in the literature (Table 1). Bergman et al. [7] noted that in such cases the inferior TA is usually of aortic origin, whereas the TA arising superiorly can be from either the renal artery or the aorta, an observation that is in accordance with our finding as well as the findings documented in the Table 1. The same authors claimed that the two TAs have an aortic and a renal origin or both may have the same origin. In addition, we detected a case of double TAs, where one artery originated from an accessory renal artery and the other artery arose from the inferior suprarenal artery, without noticing an aorta's TA origin [14]. Most authors don't mention the precise distribution of double TAs. However, Harrison and McGregor [17] mentioned that one TA which was quite straight distributed to the testis, whereas the other one TA which was undulated slightly in its course distributed to the epididymis. As it is shown in Table 1, the incidence of unilateral double TAs is varied between $1.4 \%$ and $20 \%$. From the study of Table 1 one may conclude that double TAs are originated mainly from the abdominal aorta and are mostly arisen on the left side.

TAs may be missing or arise from common stem, and one or both may be doubled, tripled or quadrupled throughout or in a particular part of their course [7]. Lippert and Pabst [22] reported double TAs on each side arising from the abdominal aorta in $2 \%$ and arising from the renal artery in $1 \%$. Harrison and McGregor [17] reported to a case of bilateral double TAs, with the TAs on both sides arising from a common trunk of aortic origin. Rusu [37] described a case of bilateral double TAs, where on the right side the superior TA originated from the superior renal artery 
Table 1. Collecting data with respect to the occurrence of double testicular arteries detected in the literature

\begin{tabular}{|c|c|c|c|c|c|c|}
\hline Authors & Incidence & $\begin{array}{l}\text { Origin from } \\
\text { aorta }\end{array}$ & $\begin{array}{l}\text { Origin from } \\
\text { renal artery }\end{array}$ & $\begin{array}{l}\text { Origin from } \\
\text { other artery }\end{array}$ & $\begin{array}{l}\text { Location on } \\
\text { the right side }\end{array}$ & $\begin{array}{l}\text { Location on } \\
\text { the left side }\end{array}$ \\
\hline Adachi (1928) [2] & $12.24 \%$ & $8.16 \%$ & $4.08 \%$ & & $4.08 \%$ & $8.16 \%$ \\
\hline Cauldwell and Anson (1936) [10] & $10.3 \%$ & & & & & \\
\hline Anson and Kurth (1955) [3] & $1 \%$ & $1 \%$ & & & & + \\
\hline Harrison and McGregor (1957) [17] & 2 case reports & 2 arteries & & & + & + \\
\hline Lippert and Pabst (1985) [22] & $20 \%$ & $15 \%$ & $5 \%$ & & $10 \%$ & $13 \%$ \\
\hline Bergman et al. (1988) [7] & $17 \%$ & & & & & \\
\hline Bergman et al. (1992) [6] & 1 case report & & 2 arteries & & + & \\
\hline Cicekcibasi et al. (2002) [11] & $6.25 \%$ & & & & & \\
\hline Loukas and Stewart (2004) [23] & 1 case report & 2 arteries & & & & + \\
\hline Bordei et al. (2004) [8] & & 7 arteries & 1 artery & & & \\
\hline Rusu (2006) [37] & 2 case reports & 2 arteries & 1 artery & & + & + \\
\hline Pai et al. (2008) [32] & $1.4 \%$ & $1.4 \%$ & & & + & \\
\hline Gurses et al. (2009) [16] & 1 case report & 1 artery & 1 artery & & + & \\
\hline Wadhwa and Sandeep (2010) [47] & $1.7 \%$ & $1.7 \%$ & & & & + \\
\hline Soni and Wadhwa (2010) [44] & 1 case report & 1 artery & 1 artery & & & + \\
\hline Kayalvizhi et al. (2011) [19] & 1 case report & 2 arteries & & & & + \\
\hline Jyothsna et al. (2012) [18] & 1 case report & 2 arteries & & & & + \\
\hline Filipovic et al. (2012) [14] & 1 case report & & 1 artery & 1 artery & & + \\
\hline Present study & 2 case reports & 3 arteries & 1 artery & & + & + \\
\hline
\end{tabular}

and inferior TA from the abdominal aorta, whereas on the left side the 2 TAs arose from a common trunk from the abdominal aorta. The uniqueness of our case is based on the following criteria: (a) It constitutes a case of true bilateral double TAs, since they are double throughout their course without emerging from a common arterial trunk. (b) The left TA displays a high origin from the abdominal aorta and specifically from the upper point of junction between aorta and left renal artery. Surprisingly, although there was a high origin of the superior left TA from the abdominal aorta, the left renal vein was situated unusually above the level of the left renal artery, leading to an arched course of TA around the renal vein. (c) The double TAs accompanied closely the TVs, as comitans arteries of the homonymous vein. We consider that TA pulsation compress the TV on both sides, likely predisposing to varicocele development.

The right TA normally courses anterior to the inferior vena cava as in our study. Occasionally, thus in $6 \%$ [29], or $10 \%$ [47] or $20 \%$ [22] the right TA is located posterior to the inferior vena cava. Notkovich [29] referred to the fact that when TA arises from the abdominal aorta above the level of the renal vein, then the right TA always passes posterior to the inferior vena cava.

As regards the level of TA's origin it is usually situated little inferior to the renal arteries [48]. Adachi [2] observed that TA originated mostly (13/31) at the level of body of the second lumbar vertebra with a following incidence of 9/31 concerning the level of the third lumbar vertebra. Cauldwell and Anson [10] found the TA's mean vertebral level of origin at the intervertebral disc between second and third lumbar vertebra (74\%) on the right side and at the lower third of second lumbar vertebra (80\%) on the left side. Wadhwa and Sandeep [47] noted that the level of TA's origin was at the body of second lumbar vertebra (76\%) on the right side and at the lower third of third lumbar vertebra (72\%) on the left side. As high origin of TA is considered the artery's origin above the main renal artery or above the second lumbar vertebra. Shoja et al. [40] detected such a high origin in $5-20 \%$ of cases. Similarly, high origin of TA above the level of the renal vein was detected in 6\% [29] and $3.3 \%$ [47]. There are not so many studies with 
respect to TA's high origin from the abdominal aorta $[9,21,30,31,34,39,49]$. In our case, the left superior TA displayed a high origin from the abdominal aorta just from the upper point of the junction between the aorta and the left renal artery.

Many case studies have been published in the literature regarding the arching course of the TA over the renal pedicle $[1,20,25,37,41]$. Notkovich [29] observed TA arising from the abdominal aorta below the level of renal vein and then arching over it making a loop in the front of the vein in $20.7 \%$ on the left side and in $7.6 \%$ on the right side. That type of TA's course was found on the left side in $23.2 \%$ [35], $1.7 \%$ [47] or $20.7 \%$ [15] and on the right side in $23.75 \%$ [15]. In our specimen, the left TA was of high origin from the abdominal aorta and arched around the left renal vein since the latter one was unusually located higher than the left renal artery. The clinical value of such a finding is based on the fact that compression of the left renal vein prior to the left TV termination may be a factor in the aetiology of a varicocele, orthostatic proteinuria and orthostatic hypertension [15]. In our specimen due to the fact that the additional TA arched around the left renal vein distal to the draining site of the ipsilateral TV, such a course could potentially lead to proteinuria and/or hypertension, but not to varicocele.

As regards the embryological development of the gonads, the latter ones are supplied from mesonephric arteries originated from the lateral aspect of aorta. In particular, nine pairs of lateral mesonephric arteries exist, constituting a cranial group from the first and second mesonephric artery arising above the celiac trunk, a middle group from the third to fifth artery providing rise to the renal arteries, and a caudal group from the sixth to ninth mesonephric arteries usually giving rise to testicular arteries $[4,13]$. When more than one artery of the middle group persist, then the accessory renal arteries are presented. The persistence of a cranial lateral mesonephric artery results in a high origin of a TA [13] as it occurs in our case where the left superior TA is of high origin from the point of junction between the abdominal aorta and the right renal artery. The persistence of one more lateral mesonephric artery on both sides explains the existence of bilateral double TAs of our case. During the ascent of the kidneys and descend of the testis, the latter one derives its arterial supply during the anterior crossing of the kidney from upper or suprarenal pedicles that are normally atrophied and from lower or subrenal pedicles that are normally dominate [36]. We consider that in our specimen the superior right TA originated from the renal artery constitutes a persistent lateral mesonephric artery of the cranial group, transferred and fused with a pre-existent mesonephric artery of the middle group, thus the renal artery. It is known that an artery may be persistent although normally obliterated as well as fused abnormally with another artery [4]. The high origin of the superior left TA is due to persistence of a suprarenal mesonephric artery as already has been aforementioned. As for the arched course of the superior left TA around the ipsilateral renal vein displayed in our case report, it has been supported that if the kidney ascends much higher, thus carrying its renal vein to a higher level than the TA's origin, the latter will be forced to follow an arched direction around that vein [29].

\section{CONCLUSIONS}

Conclusively, our case displays a unique complex of TAs variants concerning their number and source of origin. In particular, on the left side the superior TA's high origin that is likely related to haemodynamic disorders of the ipsilateral testis is associated with an unusual high location of the left renal vein leading to an arched TA's course around the vein. Such an arched TA that compresses the left renal vein could lead potentially to renal vascular hypertension, whereas the satellite two TAs accompanying the left TV could be presumably etiologic factors for varicocele's development. Moreover, on the right side apart from the double TAs accompanied the right TV, the superior TA's aberrant origin from the ipsilateral renal artery could be induced implications during embolisation of the renal artery undertaken for renal tumours' treatment. Ultimately, the awareness of such a complex combination of TAs variations should be remarkably useful for the surgeon during exploration of the area of renal pedicle, for the radiologist during performing angioplasties and interpretation of the angiographies and for the physician in general when he/she is involved in the treatment of varicocele.

\section{REFERENCES}

1. Acar HI, Yazar F, Ozan H (2007) Unusual origin and course of the testicular arteries. Surg Radiol Anat, 29: 601-603.

2. Adachi B (1928) Das Arteriensystem der Japaner. Band II, Kyoto, pp. 88-89.

3. Anson BJ, Kurth LE (1955) Common variations in the renal blood supply. Surg Gynae Obst, 100: 156-162. 
4. Arey LB (1960) Developmental Anatomy, a textbook and laboratory manual of embryology. 6th Ed. WB Saunders Co, Philadelphia, pp. 373-376.

5. Asala S, Chaudhary SC, Masumbuko-Kahamba N, Bidmos M (2001) Anatomical variations in the human testicular blood vessels. Ann Anat, 183: 545-549.

6. Bergman RA, Cassel MD, Sahinoglu K, Heidger PM Jr. (1992) Human doubled renal and testicular arteries. Ann Anat, 174: 313-315.

7. Bergman RA, Thompson SA, Afifi AK, Saadeh FA (1988) Compendium of human anatomic variation: text, atlas and world literature. Urban and Schwarzenberg, Baltimore, pp. 83.

8. Bordei P, Sapte E, Iliescu D (2004) Double renal arteries originating from the aorta. Surg Radiol Anat, 26: 474-479.

9. Brohi RA, Sargon MF, Yener N (2001) High origin and unusual suprarenal branch of a testicular artery. Surg Radiol Anat, 23: 207-208.

10. Cauldwell EW, Anson BJ (1936) The visceral branches of the abdominal aorta: topographical relationships. Am J Anat, 73: 27-57.

11. Cicekcibasi AE, Salbacak A, Seker M, Ziylan T, Buyukmumcu M, Uysal II (2002) The origin of gonadal arteries in human fetuses: anatomical variations. Ann Anat, 184: 275-279.

12. Deepthinath $R$, Satheesha Nayak $B$, Mehta RB, Bhat $S$, Rodrigues V, Samuel VP, Venkataramana V, Prasad AM (2006) Multiple variations in the paired arteries of the abdominal aorta. Clin Anat, 19: 566-568.

13. Felix W (1912) Manual of human embryology. Vol. 2. Keibel F, Mall FP eds. Lippincott, Philadelphia, pp. 820-825.

14. Filipovic B, Stijak L, Filipovic B (2012) An unusual origin of the double left testicular artery in a male cadaver: a case report. J Med Case Rep, 6: 267.

15. Grine FE, Kramer B (1981) Arched gonadal arteries in the south African negro. J Anat, 132: 387-390.

16. Gurses IA, Kale A, Gayretli O, Bayraktar B, Usta A, Kayaalp ME, Aria Z (2009) Bilateral variations of renal and testicular arteries. Int J Anatom Variations, 2: 45-47.

17. Harrison RG, McGregor GA (1957) Anomalous origin and branching of the testicular arteries. Anat Rec, 129: 401-405.

18. Jyothsna P, Mohandas Rao KG, Somayaji SN, Ashwini LS (2012) Multiple vascular anomalies involving testicular, suprarenal arteries and lumbar veins. N Am J Med Sci, 4: 154-156.

19. Kayalvizhi I, Monisha B, Usha D (2011) Accessory left testicular artery in association with double renal vessels. Folia Morphol, 70: 309-311.

20. Lelli F, Maurelli V, Maranillo E, Valderrama-Canales FJ (2007) Arched and retrocaval testicular arteries: a case report. Eur J Anat, 11: 119-122.

21. Li J, Ren ZF, Sun T (2012) Bilateral high origins of testicular arteries: a rare variant. Rom J Morphol Embryol, 53: 427-429.

22. Lippert H, Pabst R (1985) Arterial variations in man. J.F. Bergmann, Munchen, pp. 28-35.

23. Loukas M, Stewart D (2004) A case of an accessory testicular artery. Folia Morphol, 63: 355-357.

24. Mamatha H, D'Souza AS, Vinodhini P, Ray B, Suhani, Pallavi (2012) A cadaveric study about the anomalous origin of testicular arteries arising from the accessory renal arteries. Indian J Surg, doi: 10.1007/S12262-012-0737-8.

25. Mamatha Y, Prakash BS, Padmalatha K (2011) Rare variant origin of right testicular artery: a case report. Asian J Med Scien, 2: 65-67.

26. McMinn RMH (1990) Last's anatomy, regional and applied. $8^{\text {th }}$ Ed. Churchill Livihgstone, Edinburgh, pp. 363.

27. Merklin RJ, Michels RA (1958) The variant renal and suprarenal blood supply with data on the inferior phrenic, ureteral and gonadal arteries: a statistical analysis based on 185 dissections and review of the literature. J Int Coll Surg, 29: 41-76.

28. Naito M, Yi SQ, Terayama H, Hirai S, Qu N, Itoh M (2011) A left testicular artery arising from a middle mesenteric artery. Clin Anat, 24: 266-267.

29. Notkovitch H (1956) Variations of testicular and ovarian arteries in relation to the renal pedicle. Surg Gynae Obst, 103: 487-495.

30. Onderoglu S, Yuksel M, Arik Z (1993) Unusual branching and course of the testicular artery. Ann Anat, 175: 541-544.

31. Ozan H, Gumusalan Y, Onderoglou S, Simsek C (1995) High origin of gonadal arteries associated with other variations. Ann Anat, 177: 156-160.

32. Pai MM, Vadgaonkar R, Rai R Nayak SR, Jiji PJ, Ranade A, Prabhu LV, Madhyastha S (2008) A cadaveric study of the testicular artery in the South Indian population. Singapore Med J, 49: 551-555.

33. Panyanetinad O (2011) Rare combined variations of renal, testicular and suprarenal arteries. Int J Anatom Variations, 4: 17-19.

34. Paraskevas GK, loannidis O, Raikos A, Papaziogas B, Natsis K, Spyridakis I, Kitsoulis P (2011) High origin of a testicular artery: a case report and review of the literature. J Med Case Reports, 5: 75

35. Pick JW, Anson BJ (1941) The inferior phrenic artery. Origin and suprarenal branches. Anat Rec, 81: 413-427.

36. Ravery V, Cussenot O, Desgrandchamps F, Teillac P, Martin-Boyer Y, Lassau JP (1993) Variations in arterial blood supply and the risk of hemorrhage during percutaneous treatment of lesions of the pelviureteral junction obstruction: report of a case of testicular artery arising from an inferior polar renal artery. Surg Radiol Anat, 15: 355-359.

37. Rusu MC (2006) Human bilateral doubled renal and testicular arteries with a left testicular arterial arch around the left renal vein. Rom J Morphol Embryol, 47: 197-200.

38. Salve VM, Ashalatha K, Sawant S, Gajendra K (2010) Variant origin of right testicular artery: a rare case. Int J Anatom Variations, 3: 22-24.

39. Shinohara H, Nakatani T, Fukuo Y, Morisawa S, Matsuda T (1990) Case with a high-positioned origin of the testicular artery. Anat Rec, 226: 264-266.

40. Shoja MM, Tubbs RS, Shakeri AB, Oakes WJ (2007) Origins of the gonadal artery: embryologic implications. Clin Anat, 20: 428-432.

41. Singh G, Ng YK, Bay BH (1998) Bilateral accessory renal arteries associated with some anomalies of the ovarian arteries: a case study. Clin Anat, 11: 417-420.

42. Singh R, Jaiswal A, Shamal SN, Singh SP (2011) Variation in the origin of the testicular arteries and drainage of the right testicular vein. Int J Morphol, 29: 614-616

43. Siniluoto TM, Hellstrom PA, Paivansalo MJ, Leinonen AS (1998) Testicular infarction following ethanol embolization of a renal neoplasm. Cardiovasc Intervent Cardiol, 11: 162-164.

44. Soni S, Wadhwa A (2010) Multiple variations in the paired arteries of abdominal aorta: clinical implications. J Clin Diagn Res, 4: 2622-2625.

45. Stephens FD (1982) Ureterovascular hydronephrosis and the aberrant renal vessels. J Urol, 128: 984-987.

46. Tarhan S, Gümüs B, Gündüz I, Ayyildiz V, Göktan C (2003) Effect of varicocele on testicular artery blood flow in men: color Doppler investigation. Scand J Urol Nephrol, 37: 38-42.

47. Wadhwa A, Sandeep S (2010) A study of gonadal arteries in 30 adult human cadavers. Clinical Medicine Insights: Reproductive Health, 4: 1-5.

48. Williams PL, Bannister LH, Berry MM, Collins P, Dyson M, Dussek JE, Ferguson MWJ eds. (1995) Gray's anatomy. 38th Ed. Churchill Livingstone, Edinburgh, pp. 1557.

49. Xue HG, Yang CY, Ishida S, Ishizaka K, Ishihara A, Ishida A, Tanuma K (2005) Duplicate testicular veins accompanied by anomalies of the testicular arteries. Ann Anat, 187: 393-398. 